\title{
EDUTAINMENT AS A NEW TOOL FOR DEVELOPMENT
}

\author{
Kamo Chilingaryan ${ }^{1 *}$, Ekaterina Zvereva ${ }^{2}$ \\ ${ }^{1}$ Mr. Kamo Chilingaryan, RUDN University, RUSSIA, chili1@yandex.ru \\ ${ }^{2}$ Associate Prof. Ekaterina Zvereva, RUDN University, RUSSIA, frakatr@yandex.ru \\ ${ }^{*}$ Corresponding Author
}

\begin{abstract}
The modern world is changing intensively and sets new tasks for humankind. Now not only subject knowledge but also universal skills are becoming more and more in demand. They help to adapt to the environment, filled with complicated technological solutions and constant interaction with other people. These are competencies such as critical and creative thinking, the ability to communicate, working in a team, managing oneself.

Not only the school but also the family in many ways influence the formation of these skills. It is in the close circle that the child gradually masters the social norms, the rules of communication, and interaction with others through his/her practical experience.

Studies confirm that the quality of family leisure impacts the educational outcomes of the child. Moreover, the demand for high-quality family leisure on the part of parents determines the interest in the creation and development of such projects in continuing education and the socio-cultural sector.

In this article, the authors try to help outline how to develop accessible and useful educational projects (edutainment) for modern children and parents that combine family recreation and learning. The materials will help answer three crucial questions: What?; To whom?; How?
\end{abstract}

Keywords: leisure, edutainment, experience, game format, parent-child relationships

\section{INTRODUCTION}

In the last decade, Russia has undoubtedly formed a new trend for knowledge, which further has been transformed into a very stable, legitimate social phenomenon. This way, the evening pastime not to the cinema, but attending a lecture began to cause less and less surprise from the Russian progressive society.

Due to the formation of demand for knowledge, today in Russia, there are numerous international educational and entertainment formats that are developing. One of these formats is edutainment technology. This is such a form of education, which differs from the traditional educational paradigm, characterized by "fundamental", "commitment to the classics" and "installation of conservatism."

However, one cannot state that edutainment is just education and entertainment, because "entertainment" by different authors is understood differently: this is a game, digital content, creativity, living situations. Therefore, education is a more integrative concept, which, in addition to entertainment, includes both attraction and passion. 
The main goal of "edutainment" is that it helps to diversify the process of obtaining knowledge by entertainment, i.e., the theory is mixed with educational goals and means, life values and makes it possible to "present experience and entertainment through creation". However, it is worth noting that "edutainment" covers only a small part of the educational process, it only helps to diversify learning, without requiring the transformation of the traditional learning model.

MacMillan English dictionary for advanced learners (MacMillan, 2006) defines the word "education" as the process of transferring knowledge, skills and abilities on a specific subject. This definition corresponds to the Russian language version, taken, for example, from the S. Ozhegov thesaurus dictionary: "Training is the process of transferring any knowledge, skills and their further assimilation." (Ozhegov, 2006).

Based on the fact that one of the characteristic features of edutainment is the simultaneity of learning and satisfaction of one's curiosity, it can be assumed that edutainment is widely used in the learning process in general. In contrast, the satisfaction of one's curiosity, sustained interest is nothing more than a hobby (Ozhegov, 2006). Consequently, edutainment can be considered as a particular type of training, but viewed not in the narrow sense as entertainment, but rather as primary entertainment, leading to further persistent, deep passion.

\subsection{Current State of Research in the Area under Study}

"Edutainment" differs from the traditional paradigm of learning that in this case, the subject is actively involved in the learning process. He is an active consumer: expresses personal preferences, shows a subjective reaction to the experience. Thus, the interaction of an informatively entertaining object and an active subject results in getting knowledge, skills, individual experience, subjective emotions, i.e., "Edutainment". Rob Donovan, a professor at the University of Australia, refers to "edutainment" as a deliberate "combination of social order with entertainment mechanism" to quickly achieve specific goals set by society. He believes that "edutainment" is useful in gaining more information by a large number of people in a short period. (Donovan, 2010).

Moreover, the presentation of potentially complex topics takes place in a frivolous manner, which allows one to remove unwanted pressure on the psyche. Entertainment should be considered broadly: after all, this is a type of teaching that is associated not only with the entertainment mechanism but also with other processes. For example, with a social order, which means good quality education, highly qualified specialists who work with full dedication and are genuinely interested in their work.

In domestic science, there is no clear definition of "edutainment"; these are either "digital content" (O.L. Gnatyuk), "playducation" (A.V. Popov), or "creative education" (M.M. Zinovkina), or "non-formal education" (I.F. Feklistov).

Many foreign authors define "education" as "learning through entertainment." However, different sources use different verbal design. "Entertainment" is: "presenting experience and entertainment through creation" (Y. Wang); "an effective balance between information, multimedia products, psychological techniques and modern technologies (S. De Wari); combining social order with an entertainment mechanism" (R. Donovan).

Most domestic and foreign researchers believe that edutainment has incorporated the best of such areas of knowledge as:

- Pedagogy (for example, pedagogical principles);

- Psychology (communicative theory);

- Computer science (modern information and communication technologies).

\subsubsection{Communicative Theories}

According to researchers, main communicative theories - being the bases for edutainment are:

- Petty's theory of persuasion, as psychological components (improvisation, living, relaxation, reflection) affect a person's response to the message, while the degree of credibility of the message depends on the quantity and quality of the arguments and the form of their message;

- Bandura's theory of social learning, based on which human behaviour is regulated by a complex correlation of external and internal factors, which are an excellent incentive that generates an immediate reaction;

- Rogers' diffusion theory, according to which any new idea never covers a group of people as a whole for the same period, but gradually leaks through various communication channels, passing through certain stages (attention, interest, evaluation, acceptance, confirmation); 
- The concept of the collective unconscious by Jung, which admits the existence of instincts and based on which the activity of specific individuals is very subject to the influence of instincts completely independent from rational motivations of the mind.

\subsubsection{Pedagogical Principles}

Scientists are convinced that education uses such pedagogical principles as:

- The principle of the connection of theory with practice, because properly delivered training and education flows from life itself and is inextricably linked with it both through the source of knowledge and through the result itself;

- The principle of consistency, as a person has information and knowledge only when he owns a system of clearly interrelated concepts, the sequence of which is determined by the internal logic of the educational material and the cognitive capabilities of the students themselves;

- Accessibility principle, as the availability of training, is determined by the age and individual characteristics of the students, the organization of the educational process, the methods of instruction used, and others.

\subsubsection{What? (What are edutainment and its tasks)}

Any skill (including skills of the 21st century) is not enough to be understood in theory in order to learn how to apply it effectively. One can master it only by his/her own practical experience.

Edutainment, a relatively new, but rapidly gaining educational technology, helps to combine real experience with training formats. Its appearance is associated with the trends in the education of the XXI century to become much open and informal. That is, the experience that a person gets outside the walls of schools and institutions (in other areas of his life) is gradually recognized as no less, and perhaps even more critical.

The concept of edutainment consists of two words combined into one: education and entertainment. It means "learning through entertainment" and involves the introduction of gaming practices in the traditional formats of study. This approach implements two main tasks:

- It allows maintaining the interest and involvement of students;

- The game provides opportunities to create a direct experience. Training and development of skills occur directly in the learning process.

The modern word "school" comes from the ancient Greek $\sigma$ xo入ń, which means "leisure, recreation, time, free from duties and tasks." It can be said that education, combining educational and entertainment components, returns to the initial understanding of the learning process, which was founded by the ancient Greeks.

\subsubsection{The Principle of Work}

- Through game formats, adults and children are involved in the process.

- They receive positive emotions and vivid impressions, thereby maintaining interest to continue participating.

- As a result, they acquire a new experience with the ability to reflect it correctly, which leads to the conscious mastering of the skill.

However, it is essential to understand that edutainment, despite its attractiveness, is not an alternative to regular (compulsory) education. At the moment, it cannot replace traditional forms of education but instead becomes an excellent complement to them.

The ratio of educational and entertainment parts

The leaders of various educational organizations believe that their programs do not have a universal ratio of educational and entertainment elements. Instead, they try to adapt to the various demands of consumers.

In general, edutainment is a relatively new field of study and leisure, in which uniform standards have not yet been formed. Therefore, all the creators of such programs are co-creators in this lively and dynamic process and contribute to the general idea of how exactly the edutainment should be organized.

Edutainment is a trend:

According to The 2017-2022 Global Game-based Learning Market, over the past five years, the educational games market has been growing by an average of $20 \%$ per year; the most popular games are the development of practical skills (language, coding, emotional intelligence, and alike). The vanguard of the parent community is already demonstrating strong demand for this format. 


\section{MATERIALS AND DISCUSSION}

\subsection{Family Edutainment}

The majority of edutainment programs are aimed at working with elementary school students $(7-11$ years old). However, experts note that the age range is continuously expanding due to the involvement of adolescents, students, and even adults. That is, family education is gradually being formed, in which both the child and his close circle are involved.

Partially, this trend is a response to the requests of the parents themselves, because significant changes are also taking place in their relations with children. Experts stress that the following features characterize the relations of the "fathers and children" of the 21 st century:

- Parents assess their relationship with children as being closer and more trusting than those between them and their parents;

- The generation gap has been smoothed out, but misunderstanding remains since children and parents have different life experiences;

- Parents have a desire to spend more time with the child in order to get to know him and get closer.

\subsection{The Principle of Consistency}

For the sake of improving the parent-child relationships in family edutainment, the principle of consistency is used. This principle relies on the fact that learning takes place with the direct and simultaneous participation of both the child and his family members. Edutainment-events are held jointly for parents and their children. They provide an opportunity to stay close, to learn more about each other, and about mutual interests. A parent can see his child grow and develop, and begins to change with him.

In the edutainment format, different levels of parent-child interaction are possible, reflecting a gradual deepening of the contact:

- Parent - observer

- Parent -participant

- The child and the parent each perform their tasks.

- They interact with each other, work in a team.

- Roles in the team are spontaneous

- Roles are distributed

- Parent teaches

- Child teaches

\subsubsection{Problems of Consistency Vary with the Age of Children:}

\section{Pre-schoolers}

The participation of parents and joint pastime are necessary for the harmonious development of the child; the parent acts as an "assistant," a conductor between the child and the environment.

\section{$\square$ Junior and middle school age}

At this stage, it is crucial to develop the interests of the child and support his motivation to learn; the parent forms the learning culture of the family and creates a sample space in which the child can understand what attracts him.

\section{Adolescence}

Parents have a desire to spend more time with the child in order to get to know him and get closer.

\subsubsection{What is Included in the Family Edutainment Project?}

Parents and children learn the same thing in parallel: they achieve a greater understanding of each other, are "on the same wavelength." It is attractive to both the child and the parent.

Interaction via games leads to the fact that parents and children go beyond traditional roles; they can even change places. A friendly environment for dialogue, expressing any opinions is created. 
Parents get the knowledge of the importance of parent-child relationships, and they are given the opportunity for independent conclusions. There is a space for reflection after the event when both children and parents can reflect on the obtained experience. Parents and children see and begin to master the interaction scenarios that exist in other families.

\subsubsection{To Whom?}

In order to competently approach the creation and organization of edutainment programs, it is essential to start from the requests of those for whom it is intended. Here are some wishes and fears of parents regarding additional education and family leisure and, most importantly, the dreams of their children!

What do children want? "What I want, what I dream!"

It turned out that teenagers are looking for communication and vivid impressions $\rightarrow$ they strive to express themselves $\rightarrow$ they dream of being recognized $\rightarrow$ they avoid formalism and pressure.

It also became apparent that teens want to learn new things, but they do not want to do it in a "studentteacher" school format. They strive to be on equal footing with adults. Preference is given to learning, which brings tangible results in the form of the obtained ability to do something. The best way to learn new things is through actions. Along with active communications in social networks, they feel the need for direct communication and friendship.

\subsubsection{What Do Parents Want for Their Children?}

Parents of preschoolers and younger students strive to find a place in which:

- There is a diverse educational environment;

- There is respect for the personality of the child;

- Adequate attention is paid to the child's development;

- Parents are not distanced from the processes occurring with the child;

- Parents of high school students (14-17 years old) are concerned about the rapidly changing situation in the labour market. They can no longer rely on their own experience, and therefore, they trust the opinion of the child and experts more. They try to surround their children with highly qualified specialists.

\subsubsection{What Do Parents Want for Themselves?}

Very often, when choosing continuing education, parents act exclusively in the interests of the children, forgetting about their desires and needs. However, in contact with the possibilities of family edutainment, they, as a rule, are happy to open new horizons for their development. "This is emotional and intellectual relief." The joint activity brings families positive emotions, joy, and pleasure because it is interesting, and because one also faces the same challenge.

Another attractive idea is Intellectual tasks, challenges, and achievements. It is when people say: "I'm curious how other families live." Parents want that self-identification, succession to ponder, chat, express your point of view, and compare it with others. "We are interested in relating to each other," they say. They, as well, consider edutainment as a reason for meaningful communication because they want to paint, design, sculpture.

\subsection{Creativity}

What are parents afraid of?

Unfortunately, today, education and upbringing are a very stressful and even "scary" topic for an ordinary parent, which is promoted by several factors:

a) Differences in the field of education: in the bookshop, one finds "After three is already late," and next to there is "at the age of three, everything is just beginning." Moreover, which one is correct?

The conventional education system of the country acts inconsistently, first setting variability and freedom of choice, then, for some reason, introducing certain compulsory subjects to school.

Often there are scandalous discussions on the Internet and the media around teachers, schools, sections, suicide supporters, the so-called "blue whales," and alike. Grandmothers add fuel to the fire, telling mom that "she is a bad mother, and children need to be brought up differently." Furthermore, sometimes their family strategies have to be proved even to their girlfriends. 
Family edutainment has excellent potential to be a response to the acute needs of children and their parents. The variability of edutainment allows the participants to independently build or select the balance between the education and entertainment that suits them best.

Edutainment programs are built around a common task while combining different formats and adapting them to the age, abilities, and preferences of the participants. Therefore, when parents and children participate together in the program, on the one hand, everyone retains independence and gains individual experience. On the other hand, they achieve a common goal together, share ideas, help in the search for a solution. Thanks to this approach, relations between children and parents are strengthened; the need for bright educational leisure is realized.

\subsubsection{How?}

How to organize the family edutainment program in an additional education institution? Four ways to create a family edutainment can be mentioned:

- Edutainment program can be built on one or several mechanics, given below. It is vital to choose the one on which the most significant emphasis will be placed.

- The simultaneous presence of a child and a parent in a specially designed and organized environment is a positive step.

- Family interaction with a professional: a teacher and other specialists who create an edutainment situation using existing knowledge, as well as qualifications and experience (for example, Interactive Science Show Of Professor Nicolas (https://waytomonte.com/en/n-35-interactive-science-show-professor-nicolas)

The family uses a specialized technique that has been previously developed by a professional but can be implemented without the latter's direct participation. The parent and the child independently use this methodology and create an edutainment situation.

\subsubsection{How Are Key Competencies Formed in Edutainment Projects?}

\section{Learn to learn}

Edutainment encourages interest and shows that learning can be fun and exciting. A space of samples is being created, where one can understand one's own experiences and difficulties.

How to form:

- Create game simulations with the ability to try different roles;

- Create intellectual games and quests;

- Develop tasks for self-study;

- Create an environment in which participants can make independent discoveries and reflect.

Through edutainment, an environment of free creativity is made when the participants develop the rules. Tasks are set with a variety of solutions. One can creatively use himself/herself in the creation of the author's product or project.

How to make:

- Develop a discovery, creative tasks and create an environment for solving them (draw, make, do, play a role, choose an image, create a story);

- Provide opportunities for the creation of the author's creative product, for example, to release a children's collection of poems;

- Organize project activities;

- Create opportunities for improvisation.

Edutainment has the resource to create a space for choice and decision. It is crucial for immersing one's opinion in the context of others' opinions, arguing one's judgments.

\subsubsection{How to Form:}

- Create conditions for choosing and making decisions through the comparison of various options;

- Develop logical tasks and "trick questions"; 
- Create situations in which there is a need to express one's own opinions, to argue, and compare with others.

\section{Communication skills and cooperation}

Family Edutainment space involves dialogue and joint activities. It creates a safe, comfortable environment in which there are rules of interaction, statements of one's point of view.

How to form:

- Create conditions for communication with different people;

- Organize spaces for discussion and active listening;

- Ensure the participation of moderators and mediators helping to maintain a psychologically safe environment;

- Create conditions for teamwork through solving a common task or developing a universal product;

- Use team-building techniques.

\subsubsection{Checklist for Creating a Family Edutainment Program in Continuing Education}

The checklist is not final; however, it is a kind of reminder that will help the organizers to comprehensively approach the development of the program and take into account possible risks in its implementation.

1 When creating your own family edutainment program, carefully analyze the requests of the audience with which you are going to work.

2 Determine which core competencies and skills of the 21 st century your program will address.

3 Formulate a specific result that visitors of your edutainment program will receive.

4 Assess the ratio of educational and entertainment elements in it, their compliance with the needs and composition of the audience (for example, with younger children, the number of games and entertainment may well outweigh).

5 Assess how your program meets the following criteria (how much the compatibility principle is implemented):

$\checkmark$ Parents are involved, not just watching the process.

$\square$ It is attractive to both the child and the parent.

$\square$ A friendly environment for dialogue, expressing any opinions is created. There are a high-quality mediation and moderation of parent-child relationships.

$\square$ There is a space for reflection after the event, where children and parents can reflect on the experience.

6 Determine which model your edutainment will have:

- Creation of a specific material environment (for example, a museum or a park);

- Organization of space for communication of families with various specialists; parents);

- Development and use of specialized techniques (for example, an online course for children and their

- Creation a community of families.

7 Think over:

- How you see the duration and further development of your project;

- What sources of funding he/she will have

- How possible are its replication and scaling;

- How available is it to the target audience at the price, infrastructure and information.

8 Use additional recommendations on packaging and product promotion and selections of useful materials.

For the development of communication, it is necessary to rebuild the culture of communication - to move to the format of an ordinary human dialogue between all participants in the process: children, parents, and 
project organizers.

Packing and product promotion recommendations

What else is essential to pay attention to in order to make the edutainment more popular among customers:

1 parents' anxiety and stress release, i.e., informing parents, "expert customer support"; respecting the ratio of the number of children and teachers to ensure an individual approach; providing photos and videos of classes.

2 Reduced logistical difficulties: the presence in the building or the neighbouring of the full range of services; the creation of sets of classes: for example, "dancing + mathematics + English."

3 Focus on differences from regular school, kindergarten, and others. For example, gather your team and create a list of 10 points about their qualitative differences.

4 Expert confirmation of methods, technologies, and teachers (availability of certificates, official expert opinions, and others).

5 Availability of exciting and original educational formats (visits to museums, "walks in English," quests, mathematical fights, meetings with interesting people, practical work, field research, educational trips, and others).

6 Possibility of professional testing and the choice of the child of his path: it is necessary to develop a fullfledged high-quality work so that adolescents can independently try themselves in various professions, discuss with specialists and reflect on their choices.

\section{CONCLUSION}

In conclusion, it can be noted that when using the technology of edutainment, it is necessary to encourage students at least once to pay attention to the material being studied, arouse their interest in it, motivate them to participate in the educational process, or shortly said - to entertain. Then, during the process of obtaining knowledge, it is necessary to give students the pleasure of acquiring this knowledge, to fully absorb them and distract from third-party thoughts or experiences, namely, to attract.

Ultimately, it is necessary to help students achieve complete emancipation in the learning process, to form a keen interest in the learning process, and therefore - to "captivate".

Therefore, "education" is a particular type of training, which is based on entertainment and the formation of primary interest in the subject with getting pleasure from the learning process and a persistent interest in the learning process.

The authors express their hope that the materials presented here will be useful for readers and will help them in creating their educational programs based on continuing education institutions. Namely, they will give answers to three key questions:

- The kind of technology and the possibility to master the skills of the 21 st century through the game. Special attention here was paid to family education as a form of joint, useful leisure for children and their parents, within which the relations between family members are improved, their mutual understanding and communication with each other are strengthened. (What?)

- The primary requests of the target audience of family education - children and their parents. (To whom?)

- How to organize one's educational project: what criteria to rely on, what models and technologies to use, what to take into account, and others. For the convenience of the reader, we have compiled a checklist describing the steps that need to be taken when planning an educational program. (How?)

\section{ACKNOWLEDGEMENT}

This article has been prepared in the framework of RUDN University participation of Russia-wide 5-100 program. 


\section{REFERENCE LIST}

De Vary, Sh. (2008). Educational Gaming. Interactive Edutainment. Distance learning: For Educators, Trainers and Leaders. Vol. 5, Issue 3, No. 3. Boston, Information Age Publishing. pp. 35—44.

Donovan, Rob, (2010). Henley Nadine Principles and Practice of Social Marketing, an International Perspective. Cambridge: Cambridge University Press, p. 504.

Feklistov I.F. (2002). A manual on human rights education with the youth. Moscow, Council of Europe, 478 p.

Gnatyuk, O. (2010). Bases of communication theory. Moscow. KNORUS, 256 p.

http://seriousplayconf.com/wp-content/uploads/2017/07/Metaari_2017-2022_Global_Gamebased_Learning_Market_Executive_Overview.pdf

https://waytomonte.com/en/n-35-interactive-science-show-professor-nicolas

Macmillan English Dictionary for Advanced Learners. (2006) London: Bloomsbury Publ. Plc., 1692 p.

Ozhegov, S.I., Shvedova, N.Yu. (2006). Thesaurus Dictionary of the Russian Language: 80,000 words and phraseological expressions / Russian Academy of Sciences. Russian Language Institute after V.V. Vinogradov. - 4th ed., Revised. Moscow, TEMP, 944 p.

Wang, Ya. (2007). Edutainment technology - a new starting point for education development of China, Section T1B-5, 37th ASEE/IEEE Frontiers in Education Conference, WI, Milwaukee. pp. 10-13.

Zinovkina M.M. (2007). Pedagogical creativity / Modular-coded textbook. Moscow, MGIU, 258 p.. 